\title{
Tuberculosis in aboriginal Canadians
}

\author{
Vernon H Hoeppner MD FRCPC, Darcy D Marciniuk MD FRCPC \\ Division of Tuberculosis Control, Department of Medicine and Research Centre \\ for the Elimination of Tuberculosis, University of Saskatchewan, \\ Saskatoon, Saskatchewan
}

\section{VH Hoeppner, DD Marciniuk. Tuberculosis in aborigi- nal Canadians. Can Respir J 2000;7(2):141-146.}

Endemic tuberculosis (TB) was almost certainly present in Canadian aboriginal people (aboriginal Canadians denotes status Indians, Inuit, nonstatus Indians and metis as reported by Statistics Canada) before the Old World traders arrived. However, the social changes that resulted from contact with these traders created the conditions that converted endemic TB into epidemic TB. The incidence of TB varied inversely with the time interval from this cultural collision, which began on the east coast in the 16th century and ended in the Northern Territories in the 20th century. This relatively recent epidemic explains why the disease is more frequent in aboriginal children than in Canadian-born nonaboriginal people. Treatment plans must account for the socioeconomic conditions and cultural characteristics of the aboriginal people, especially healing models and language. Prevention includes bacillus Calmette-Guerin vaccination and chemoprophylaxis, and must account for community conditions, such as rates of suicide, which have exceeded the rate of TB. The control of TB requires a centralized program with specifically directed funding. It must include a program that works in partnership with aboriginal communities.

Key Words: Aboriginal people; Epidemiology; History; Tuberculosis; Vaccination

\section{La tuberculose chez les aborigènes du Canada}

La tuberculose (TB) endémique existait probablement dans les populations aborigènes du Canada (définies par Statistique Canada comme les Indiens enregistrés, les Inuit, les Indiens non enregistrés et les Métis) avant l'arrivée des marchands de l'ancien monde. Cependant, les changements sociaux qui ont résulté des contacts avec ces marchands ont créé des conditions qui ont transformé la TB endémique en TB épidémique. L'incidence de TB a varié inversement avec l'intervalle de temps à partir de ce choc culturel, qui a débuté sur la côte Est au $16^{\mathrm{e}}$ siècle et s'est terminé dans les Territoires du Nord au $20^{\mathrm{e}}$ siècle. Cette épidémie plutôt récente explique pourquoi la maladie est plus fréquente chez les enfants aborigènes que dans les populations non aborigènes nées au Canada. Les plans de traitement doivent tenir compte des conditions socio-économiques et des caractéristiques culturelles des populations aborigènes, en particulier, des modèles de guérison et de la langue. La prévention comprend la vaccination au bacille CalmetteGuérin (BCG) et la chimioprophylaxie, et doit tenir compte des conditions qui prévalent dans les communautés, comme les taux de suicide, qui dépassent les taux de tuberculose. Le contrôle de la TB nécessite un programme centralisé avec un financement dirigé vers des besoins spécifiques. Il doit aussi comprendre un programme qui fonctionne en partenariat avec les communautés aborigènes. 
$\mathrm{B}$ efore the 15th century explorations of North, South and Central America by Old World traders, there was a thriving culture of aboriginal people that numbered about 100 million, of which 20 million lived in North America $(1,2)$. Within 200 years of the arrival of the Old World traders, this population declined by $95 \%$ (1). It was widely believed that the decline resulted from communicable diseases, including tuberculosis (TB), that the Old World traders brought with them.

Was TB an imported disease? Burial remains of aboriginal people in Peru, dated to about $700 \mathrm{AD}$ (3) and 1000 AD, have been found with organisms confirmed to be Mycobacterium tuberculosis complex with DNA fingerprinting (4) (this does not differentiate Mycobacterium bovis from Mycobacterium tuberculosis); remains of aboriginal people found in Saskatchewan have been dated to about 900 AD (5), and in Ontario, dated to about $1490 \mathrm{AD}(6)$, all showing that TB existed in the Americas before the Old World traders arrived. In fact, TB had infected humans worldwide for thousands of years already (7).

The epidemic was probably brought from the Old World, more through cultural influences than through microbes. The contact between the Old and New World irrevocably changed the New World culture that had been painstakingly developed and proven over centuries (1). The New World evolved from pastoral-nomadic societies to communitystationary societies in less than a decade, making its members vulnerable to communicable diseases that included TB (8), and playing a role in converting the endemic to an epidemic.

\section{EPIDEMIOLOGY OF TB AMONG ABORIGINAL CANADIANS}

In Canada, the incidence of TB in the aboriginal population varied inversely with the time interval from the cultural

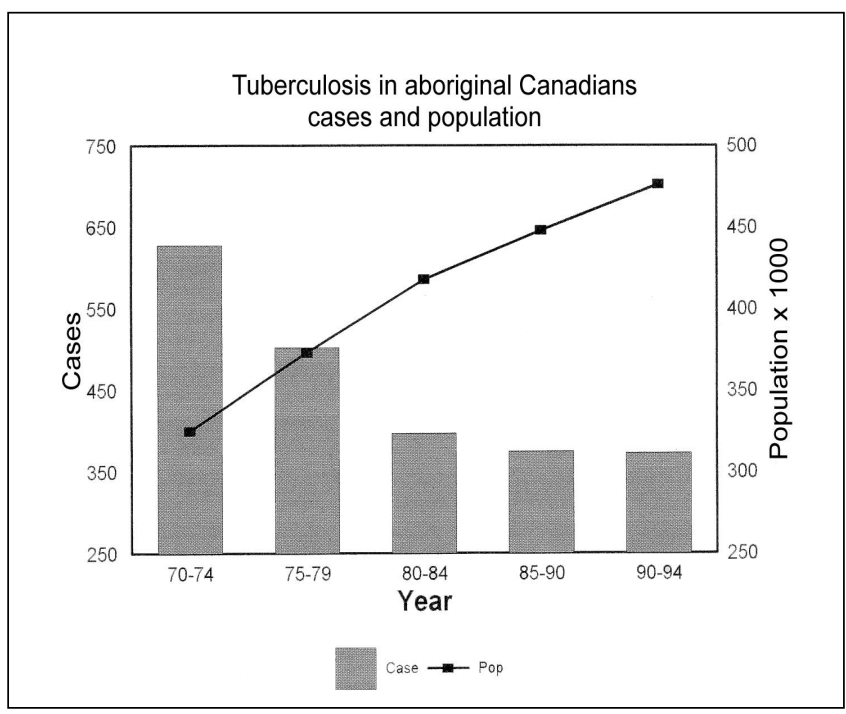

Figure 1) The bars are the number of tuberculosis cases and the line is the population in five-year means in aboriginal Canadians. The 1970 to 1974 rate was 193 cases per 100,000 population/year and the 1990 to 1994 rate was 78 cases per100,000 population/year. Data adapted from references 12 and 13 collision (9). This fits the Grigg theory of natural selection (8). When an epidemic wave begins, most disease occurs in the young, the most susceptible members of the population. Most infected persons develop the disease and die. Each death removes susceptible members from the population, leaving the remaining population more resistant. All infected persons no longer develop disease, and not all diseased persons die. As the epidemic progresses over time, the resistance of the population increases.

In describing aboriginal TB of the latter 19th century, George Ferguson wrote that '... prior to the disappearance of the buffalo from their territory in 1879 , it is certain that there were sporadic cases of tuberculosis, and equally certain that it was uncommon and unimportant as a cause of death "(10). The disappearance of the buffalo was the legacy of the Old World culture. It transformed the 12,000-year aboriginal way of life $(1,2)$ over two years, which is the anthropological equivalent of an eye blink.

"The captain of the men of death" (11) came with this transformation. The death rate from TB around Fort Qu'Appelle, Saskatchewan rose from nothing before 1880 to 40 per 1000 people in 1882 to 137 per 1000 people in 1890 . By 1926, this diminished to 40 per 1000 . The disease was mostly in children and disseminated (10).

Between 1970 and 1994, the number of new and relapsed cases in the Canadian aboriginal people decreased from 628 to 373 (Figure 1) (12). During the same interval, the population rose from 325,000 to 476,000 (13). The rate of new and relapsed cases $/ 100,000$ decreased by $60 \%$, from 193 to 78 . In 1991 , less than half of all cases occurred in children under the of age 20 years (46\%) (12). This correlated with the age of the population $-45 \%$ being under age 20 years (13).

The trends were similar, but the rates varied in all regions as they did in 1970 to 1974 (Table 1). These rates were substantially lower than those in 1970 to 1974 , but the inverse relationship between TB rates and the interval from first contact with Old World traders remained (Figure 2).

Although the rate of TB infection decreased by $60 \%$, the rate of decrease lagged behind the nonaboriginal Canadian population. In 1970, the aboriginal rate was 12 times higher than the nonaboriginal rate, with 212 cases per 100,000 population compared with 17 (Figure 3). In 1995, the aboriginal rate was 39 times higher, with 70 cases per 100,000

\section{TABLE 1}

The times of first contact with the Old World traders and the rates of tuberculosis in status Indians are listed by region in five-year means for the period 1970 to 1974 (9) and 1990 to $1994(12,13)$

\begin{tabular}{llcc}
\hline Region & First contact & $\begin{array}{c}\text { Rate } \\
\text { (1970 to 1974) }\end{array}$ & $\begin{array}{c}\text { Rate } \\
\text { (1990 to 1994) }\end{array}$ \\
\hline Atlantic & 17th Century & 100 & 7 \\
Pacific & 18th Century & 125 & 52 \\
Prairies & 19th Century & 225 & 79 \\
Territories & 20th Century & 250 & 97 \\
\hline
\end{tabular}

While the rates decreased over 20 years, the pattern between the regions remained the same 


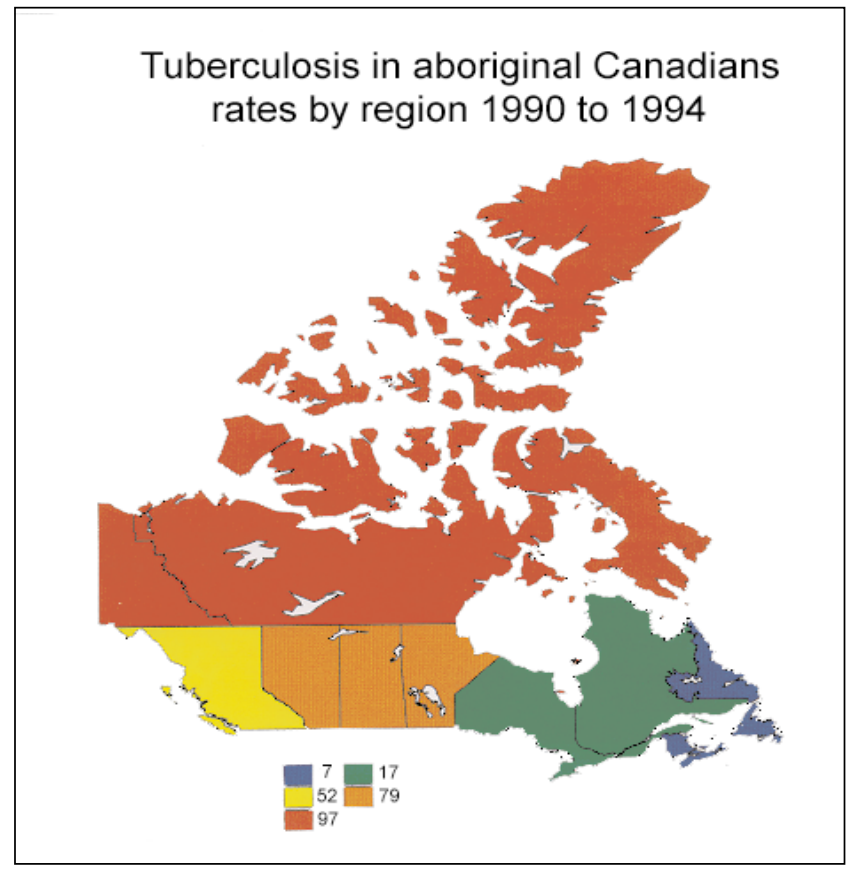

Figure 2) This figure maps the rate (number of new cases per 100,000/year) of tuberculosis across Canada. The blue areas (Maritimes) indicate a rate of seven, green (Ontario and Quebec) indicates a rate of 17, yellow (British Columbia) equals 52, orange (Prairies) equals 79 and red (territories) denotes an infection rate of 97 . The highest rate of tuberculosis was in the north

population compared with 1.8. This resulted from decreasing infection rates in nonaboriginal Canadians, while aboriginal rates were stable or rising as they were in Western Ontario (14) and Vancouver (15).

The different rates of decrease despite uniform strategies of control for both populations suggests that the aboriginal people require a different strategy $(14,16)$. The 20 -year decrease from a rate of 250 cases per 100,000 population to 97 in the Territorial aboriginal people suggests that these rates would be reduced to about 40 in the next 20 years using current strategies for control. Eliminating TB will require enhanced strategies and funding.

\section{TYPE AND EXTENT OF DISEASE}

The characteristics of TB differ strikingly between Canadian-born aboriginal and nonaboriginal populations. In $1990,52 \%$ of aboriginal patients were under age 25 years and $11 \%$ were over age 65 years, compared with $8 \%$ and $42 \%$, respectively, of nonaboriginal cases. Thirty-seven per cent of aboriginal cases were primary compared with $5 \%$ of nonaboriginal people (12).

The main methods for detecting TB are the recognition of presenting symptoms, contact tracing and screening procedures. By the time symptoms appear, the disease is usually advanced, characterized by cavities on chest radiograph and positive smears on microscopy. In 1990, $81 \%$ of nonaboriginal patients were detected through symptoms; $52 \%$ had cavities and $61 \%$ had smear-positive microscopy.

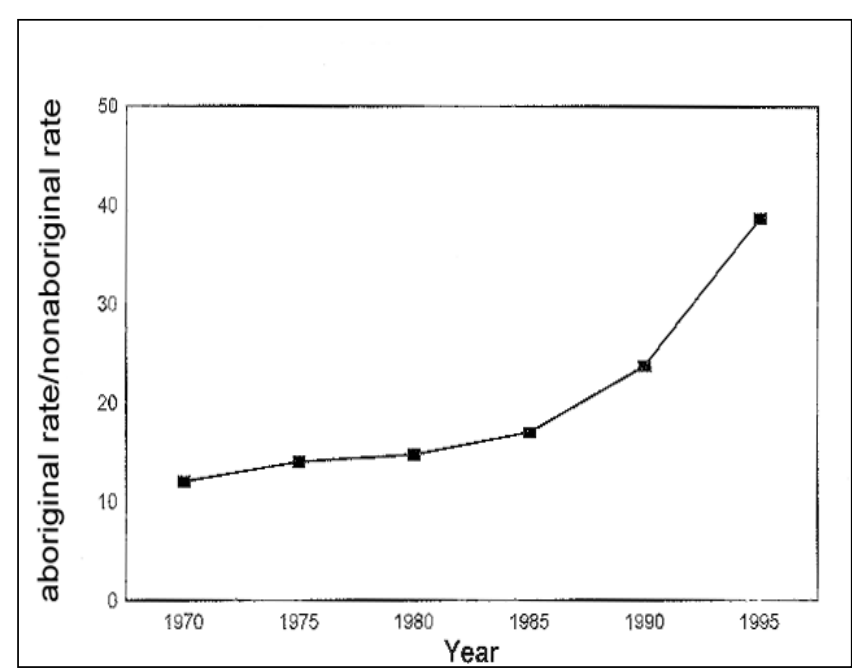

Figure 3) Tuberculosis in aboriginal Canadians - relative rate to nonaboriginals. The relative rate was obtained by dividing the aboriginal rate by the nonaboriginal rate. Each point is a three-year mean. The 1970 relative rate was 12; the 1995 relative rate was 39 . Data adapted from reference 12

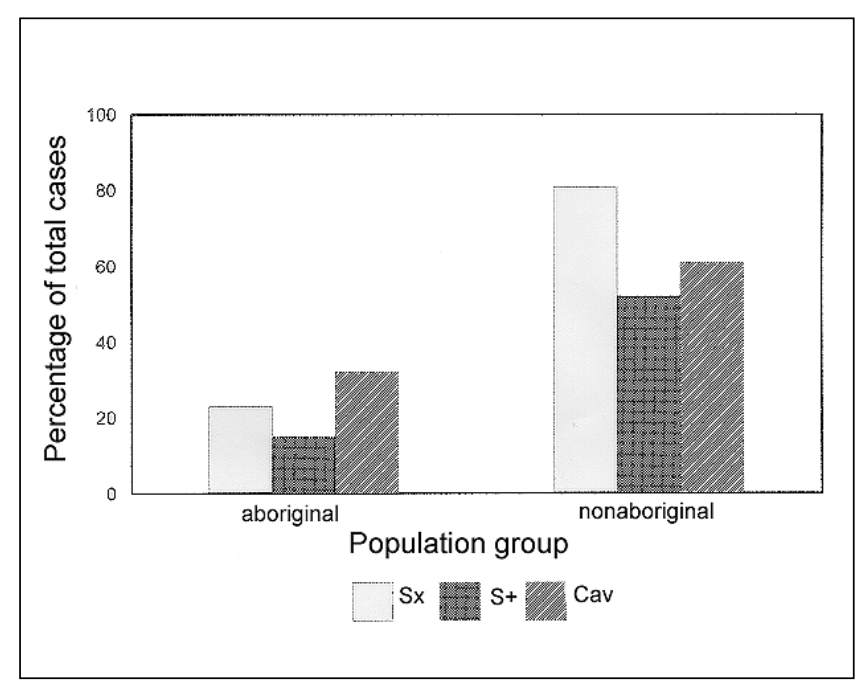

Figure 4) Tuberculosis in Canadian-born persons - extent of the disease 1990. A correlation of the extent of the disease in the aboriginal and nonaboriginal patients who presented with symptoms. The number of aboriginal patients with symptoms was low; the number with smear-positive microscopy and the number with cavities on chest radiograph was low. The number of nonaboriginal patients presenting with symptoms was high; the number with smear positive microscopy and the number with cavities on chest radiograph was high (ie, they had more advanced disease). Cav Chest $x$-ray cavities; S+ Smear-positive microscopy; Sx Symptoms. Data adapted from reference 12

Twenty-three per cent of aboriginal patients were detected through symptoms; $15 \%$ had radiographic cavities and $32 \%$ had positive smears on microscopy (Figure 4) (12).

The prevalence of advanced disease was lower in aboriginal people than in nonaboriginal people. The corollary is that in patients who were detected in contact or screening programs, often before symptoms appeared, the disease was less 
advanced. Patients have been found before they are infectious with the use of screening programs that are available in remote areas of the country, such as on reservations (14).

Greater differences were noted between aboriginal and nonaboriginal populations (17) when TB was detected because of symptoms. There was a higher incidence of peritoneal (18) and ocular (19) TB, and a higher incidence of morbidity and mortality in all presentations in aboriginal populations (20). While the incidence of miliary TB was higher in aboriginal patients, the mortality was less, probably because of the younger age of aboriginal patients (21).

When the suspicion for TB is low, it is sometimes only found at autopsy. Therefore, autopsy prevalence of TB is related to the index of suspicion and the incidence of $\mathrm{TB}$ in the community. The prevalence of TB found at autopsy in 1967 in aboriginal Americans was 8.3\% (22). The autopsy prevalence was also related to socioeconomic and environmental factors, the same factors that contributed to the higher incidence of TB in aboriginal populations. As TB rates decreased, autopsy prevalence of TB decreased from $9.7 \%$ in 1958 to $4.7 \%$ in 1968 (23). In Canada in 1990, autopsy was the method for detection of $1 \%$ of aboriginal cases of TB compared with $3 \%$ of nonaboriginal cases (12).

\section{TREATMENT}

The objectives in the control of TB include preventing transmission of infection, drug resistance, relapse and disease in infected persons. Factors such as homelessness, overcrowding, poor nutrition, poverty, alcoholism, frequent migration between reservation and urban centres, misunderstandings regarding $\mathrm{TB}$ and drug resistance complicate the management of the disease (24). These factors must be appreciated when developing treatment plans, and this can be accomplished by including aboriginal health care workers (HCWs) in such plans (25).

A high risk of relapse was reported when the initial disease was extensive (16). This was likely because of incomplete therapy, inadequate access to health care, poor living conditions, a higher prevalence of inactive TB and a higher risk of relapse following inadequate chemotherapy compared with nonaboriginal people (26). The important outcome determinant was compliance with anti-TB regimens. This was improved with directly observed therapy (DOT), (27) an important step (14) second only to early diagnosis. DOT was effective and economical on reservations, with savings of US $\$ 9,000$ to US $\$ 14,000$ per patient (28).

HCWs predicted compliance poorly (29) because it was not predicted by age, sex, religion, education, race or socioeconomic status. Moreover, compliance was reduced when the treatment was shifted from aboriginal to nonaboriginal HCWs (30). Effective treatment is dependant on the HCW's compatibility, awareness and sensitivity to cultural differences (31). This highlights the importance of attaching nonaboriginal health care delivery to aboriginal healing models, and acknowledging that both models can coexist (31).

Previously, TB in aboriginal patients included involuntary admission to a sanatorium - institutions that were distant in miles and culture (32). Advances in treatment led to sanatoria closure and cessation of involuntary admissions. This helped the aboriginal people to accept contemporary treatment. However, attitudes are still shaped by the experience of nonaboriginal models of treatment of the 1940s, when, for example, aboriginal people in British Columbia did not receive the same treatment as nonaboriginal people (33).

While complicating management, drug resistance did not contribute to the higher incidence of TB in aboriginal people (24). Drug resistance rates were similar to those in nonaboriginal patients and lower than in foreign-born patients (24). In 1990, Canadian drug resistance was reported in $1.3 \%$ of aboriginal patients, $1.7 \%$ of nonaboriginal patients and $8.6 \%$ of foreign-born patients (12). Nonetheless, the possibility for drug resistance exists in this population where language, cultural and geographic barriers may interfere with effective treatment. Drug resistance can be attributed to poor drug delivery programs and poor patient compliance (34).

\section{PREVENTION}

Preventive treatment is an effective means of preventing TB in infected people. Vancouver inner-city aboriginal people had a higher prevalence of infection than nonaboriginal Canadians (35). Elsewhere, up to $50 \%$ of 20 -year-old aboriginal people were infected (14). A steady stream of TB flowed from this reservoir of infection (16). The number of new cases/100,000 people in 1991 in aboriginal people less than 25 years of age was 69 compared with 0.5 in nonaboriginal people. Most of these cases could have been prevented with isoniazid (INH) prophylaxis (36). This age group tolerated INH well (37). Thus, directed screening can be effective in preventing TB when used in high prevalence areas $(14,32)$.

The efficacy of preventive treatment with INH and with INH and ethambutol has been established $(36,38)$, but the use of INH must be weighed against the frequency of attempted suicide. The $8.3 \%$ risk of dying from an INH overdose approached the $10.2 \%$ risk of dying from traumatic suicide in Arizona aboriginal people (39), in whom the rate of suicide attempts, 180, exceeded the rate of TB, 124. There was an overlap in the aboriginal people with self-destructive behavior who were also at risk for developing TB (40). In these patients, TB control requires (39):

- careful selection of patients for INH prophylaxis;

- dispensing small amounts at short intervals;

- close monitoring of compliance with the prescribed drug regimen; and

- dispensing individually wrapped tablets to inhibit the impulsive ingestion of massive amounts of the drug.

Such measures incorporate the view that TB control efforts must account for the cultural characteristics of the aboriginal community (41).

Willingness and reliability in taking INH preventive treat- 
ment influences the efficacy of preventing TB. Compliance rates as low as 5\% (doses taken and/or doses prescribed) have been reported in a Canadian aboriginal community (42). The outcome was improved with directly observed prophylaxis that also eliminated the risk of suicidal overdoses.

Aboriginal newborns are the only population in Canada for whom bacillus Calmette-Guerin (BCG) vaccination is recommended as policy (43). While there have been questions about the efficacy of BCG (44), the protective effect was as high as $60 \%$ in Manitoba (45), 57\% in Alberta (46) and $80 \%$ in Saskatchewan (47).

\section{THE ORGANIZATION OF TB CONTROL PROGRAMS}

In 1990, the Conjoint Committee on Communicable Disease Control of Medical Services Branch, Health Canada, Ottawa, Ontario identified TB as the disease that required special attention. A Strategy for the Elimination of Tuberculosis was drafted in September 1993.

An important recommendation was to introduce a centrally organized program to develop, monitor, coordinate and evaluate the control and treatment of TB. The strategy was based on adequate resources and forging partnerships between TB control programs, community health agencies and communities.

There is considerable pressure to devolve the centrally coordinated and funded TB program to the health service delivery units. Historically, devolution has not helped TB programs. In citing what was needed, the 1995 Lancet Conference on the Challenge of Tuberculosis (48) emphasized the importance of specialized clinics:

... that in all developed countries past successes in the control of tuberculosis have been obtained through strictly (specialized) programs and that in endemic countries where the tuberculosis control program has been (combined with other health care programs), the control of tuberculosis has been unsuccessful.

This conclusion was confirmed by the American experience:

The USA has finished its second consecutive year of reduction of tuberculosis cases ... the reasons for the tragic resurgence of tuberculosis ... is even more easily demonstrated - erosion of state level tuberculosis control programs under the failed block grant funding experiments of the 1970s (49).

\section{WHAT IS NEEDED}

- Finding cases early.

- Suspect TB in persons with cough for more than one month or unexplained fever for more than a week

- Timely comprehensive contact tracing

- Screening programs in high prevalence communities and institutions

- Completion of treatment.

- DOT
- Prevention.

- BCG vaccination of newborns

- Skin test screening programs in high prevalence communities

- Preventive treatment for persons with a high risk of developing TB

- Research.

- Improving methods of diagnosis

- Improving methods for preventing the disease in infected persons

- Improving the efficacy of vaccination

- Improving methods of treatment

- Improving methods for preventing the spread of infection

- An elimination strategy.

- Introduce a centralized organizational structure to develop, coordinate and evaluate the program

- Coordinated partnerships of communities, health service delivery agencies and the TB program

- Adequate centralized funding designated for TB control

\section{CONCLUSIONS}

This review of TB in aboriginal Canadians shows that the rates of the disease are higher and declining at a slower rate than in nonaboriginal Canadians despite identical strategies for control. The control of TB in aboriginal Canadians requires a shift in strategy and a greater effort. Strategic shifts include:

- Active case finding through surveillance in high risk groups to increase early detection;

- DOT for all cases;

- Employing lay community-based aboriginal HCWs within a program that is compatible, aware and sensitive to cultural characteristics;

- Directed screening - the school population is feasible - in high prevalence areas to find infected persons;

- Directly observed prophylaxis in infected persons who are at high risk (young children) of developing TB;

- A centralized program with TB specialist HCWs and directed TB funding administered by the central program with the mandate that the funds cannot be used for non-TB programs.

We cannot afford not to make a greater effort. The status quo will give us continuing high rates of TB morbidity and mortality and with it a growing proportion of untreatable TB in the form of drug resistance. 
ACKNOWLEDGEMENTS: We gratefully acknowledge the late Anna Brancker, Senior Analyst, and Kitty Wilkins, Senior Analyst, Statistics Canada for providing the data; Catherine Ulmer, Regional Nursing Officer, Medical Services Branch, Saskatchewan Region, for providing pertinent Medical Services Branch structural information; and Candace Leuschen and Darlene Nadon in the preparation of this manuscript. Dr Marciniuk is a Saskatchewan Lung Association Research Scholar

\section{REFERENCES}

1. Wright R. Stolen Continents. Toronto: Penguin Books Canada Limited, 1992:3-14

2. Dickason OP. Canada's First Nations. Toronto: McClelland \& Stewart Inc, 1992:20-35.

3. Allison MJ, Mendoza D, Pezzia A. Documentation of a case of tuberculosis in pre-Columbian America. Am Rev Respir Dis 1973;107:985-91.

4. Caravan FB. Peruvian mummy shows that TB preceded Columbus. Br Med J 1994;308:808.

5. Walker EG. The Woodlawn site: A case for the interregional disease transmission in the late prehistoric period. Can J Archeol 1984;7:49-59.

6. Pfeiffer S. Paleopathology in an Iroquoian Ossuary, with special reference to TB. Am J Phys Anthrop 1984;65:181-9.

7. Bloom BR, Murray CJL. Tuberculosis: commentary on a re-emergent killer. Science 1992;257:1055-64.

8. Grigg ERN. The arcana of tuberculosis. Am Rev Tuberc Pulm Dis 1958;78:151-72, 426-53, 583-95.

9. Grzybowski S. Epidemiology of TB and the role of BCG. Clin Chest Med 1980;1:175-87.

10. Ferguson RG. TB Among the Indians of the Great Canadian Plains. London: Adlard and Son, 1928.

11. Bunyan J. The Life and Death of Mr Badman. London: Dent, 1928.

12. TB data: Canadian Centre for Health Information. 1970-1994. Ottawa: Statistics Canada.

13. TB Data: Canadian Centre for Health Information. Population projections of registered Indians, 1982 to 1996, January 1990 (based on medium growth assumptions). Ottawa: Indian and Northern Affairs Canada.

14. Young TK, Casson RI. The decline and persistence of TB in a Canadian Indian population: implications for control. Can J Pub Health 1988;79:302-6.

15. Enarson DA, Wang J, Dirks JM. The incidence of active TB in a large urban area. Am J Epidemiol 1989;129:1268-76.

16. Johnson, IL, Thompson M, Manfreda J, Hershfield ES. Risk factors for reactivation of TB in Manitoba. CMAJ 1985;133:1221-4.

17. Buchholz CJ, Dean RE. Tuberculosis in the Dakota Sioux. SDJ Med 1978;31:23-5.

18. Jakubowski A, Elwood RK, Enarson DA. Clinical features of abdominal tuberculosis. J Infect Dis 1988;158:687-92.

19. Wyatt HT. Corneal disease in the Canadian north. Can J Ophthalmol 1973;8:298-305.

20. Galbraith JD, Gryzbowski S, Law CL, Rowe J. Tuberculosis in Indian children: primary pulmonary tuberculosis. CMAJ 1969;100:497-502.

21. Campbell IG. Miliary tuberculosis in British Columbia. CMAJ 1973;108:1517-26.

22. Reichenbach DD. Autopsy incidence of disease among southwestern American Indians. Arch Path 1967;84:81-6.

23. Arthaud JB. Cause of death in 339 Alaskan Natives as determined by autopsy. Arch Path 1970;90:433-8.

24. Long R, Manfreda J, Mendella L, Wolfe J, Parker S, Hershfield E. Antituberculous drug resistance in Manitoba from 1980 to 1989. CMAJ 1993;148:1489-95.
25. Dohner VA. Tuberculosis treatment - letter. JAMA 1973;226:73.

26. Nakielna EM, Cragg R, Grzybowski S. Lifelong follow-up of inactive tuberculosis: its value and limitations. Am Rev Respir Dis 1975;112:765-72.

27. Weis SE, Slocum PC, Blais FX, et al. The effect of DOT on the rates of drug resistance and relapse in TB. N Engl J Med 1994;330:1179-84

28. Mikkelson MK, Snoke T, Sharp C, Westley T, Vall-Spinosa A Ambulatory tuberculosis chemotherapy on an Indian Reservation. Chest 1973;64:570-3.

29. Cramer JA, Mattson RH, Prevey ML, Scheyer RD, Ouellete VL. How often is medication taken as prescribed? - a novel assessment technique. JAMA 1989;261:3273-7.

30. Rideout M, Menzies R. Factors affecting compliance with preventive treatment for tuberculosis at Mistassini Lake, Quebec, Canada. Clin Invest Med 1994;17:31-6.

31. Deushle KW. Cross-cultural medicine: The Navajo Indians as case exemplar. Daedalus 1986;Spring:175-84.

32. Tempest P, Pesanti E Jr. A community-wide tuberculosis case finding program on the Navajo reservation. Am Rev Respir Dis 1974;110:760-4.

33. Jenkins D. Tuberculosis: the native Indian viewpoint on its prevention, diagnosis and treatment. Prevent Med 1977;6:545-55.

34. Neville K, Bromberg A, Bromberg R, Bonk S, Hanna BA, Rom WN. The third epidemic - multidrug-resistant tuberculosis. Chest 1994;105:45-8.

35. Grzybowski S, Allen EA, Black WA, et al. Inner-city survey for tuberculosis: evaluation of diagnostic methods. Am Rev Respir Dis 1987;135:1311-5

36. Comstock GW, Ferebee SH, Hammes LM. A controlled trial of community-wide isoniazid prophylaxis in Alaska. Am Rev Respir Dis 1967;95:935-43

37. Dash LA, Comstock GW, Flynn JP. INH preventive treatment. Am Rev Respir Dis 1980;121:1039-44.

38. Grzybowski S, Galbraith JD, Dorken E. Chemoprophylaxis trial in Canadian Eskimos. Tubercle 1976;57:263-9.

39. Sievers ML, Cynamon MH, Bittker TE. Intentional isoniazid overdosage among southwestern Indians. Am J Psych 1975;132:662-5

40. Resnick HLP, Dizmang LH. Observations on suicidal behavior among American Indians. Am J Psych 1971;127:882-7.

41. Beilby J, Reed J, Baker J, et al. Tuberculosis surveillance in the south Australian aboriginal community. Med J Aust 1990;153:149-55.

42. Wobeser W, To T, Hoeppner VH. The outcome of chemoprophylaxis on tuberculosis prevention in the Canadian Plains Indian. Clin Invest Med 1989;12:149-53.

43. Young TK, Mirdad S. Determinants of tuberculin sensitivity in a child population covered by mass BCG vaccination. Tuberc Lung Dis 1992:3:94-100.

44. Young TK. A BCG trial in Canada's native populations - letter to the editor. CMAJ 1982;127:127-8

45. Young TK, Hershfield ES. A case-control study to evaluate the effectiveness of mass neonatal BCG vaccination among Canadian Indians. Am J Pub Health 1986;76:783-6.

46. Houston S, Fanning A, Soskolne CL, Fraser N. The effectiveness of bacillus Calmette-Guerin (BCG) vaccination against tuberculosis. Am J Epidemiol 1990;131:340-8.

47. Ferguson RG, Sime AB. BCG vaccination of Indian infants in Saskatchewan. Tubercle 1949;30:5-11.

48. Enarson DA, Grosset J, Mwinga A, et al. The challenge of tuberculosis: statements on global control and prevention. Lancet 1995;346:809-19.

49. Reichmann LB. How to ensure the continued resurgence of tuberculosis. Lancet 1996:347:175-7. 


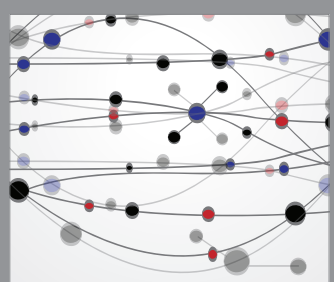

The Scientific World Journal
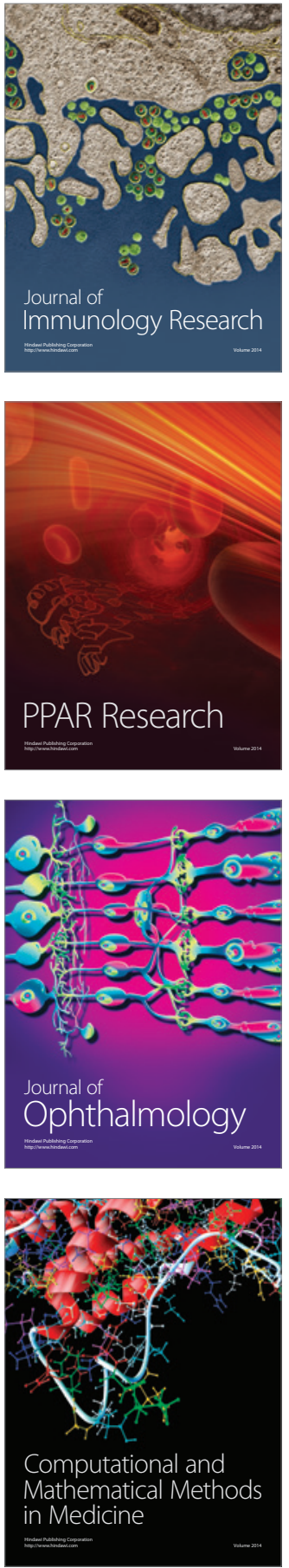

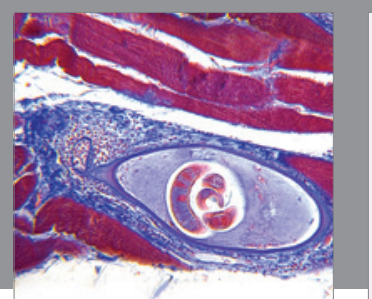

Gastroenterology Research and Practice

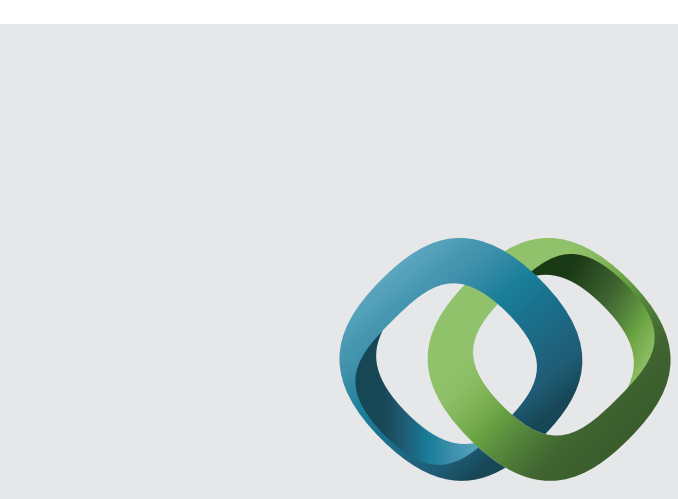

\section{Hindawi}

Submit your manuscripts at

http://www.hindawi.com
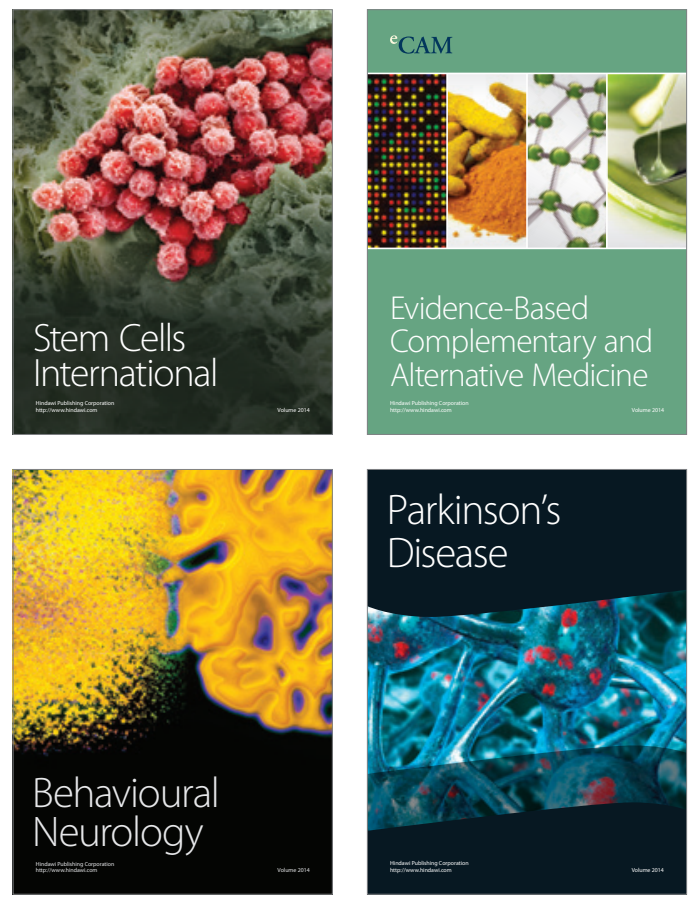
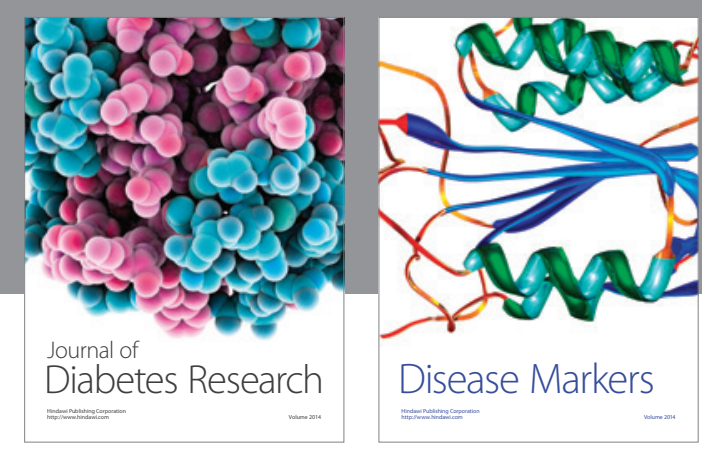

Disease Markers
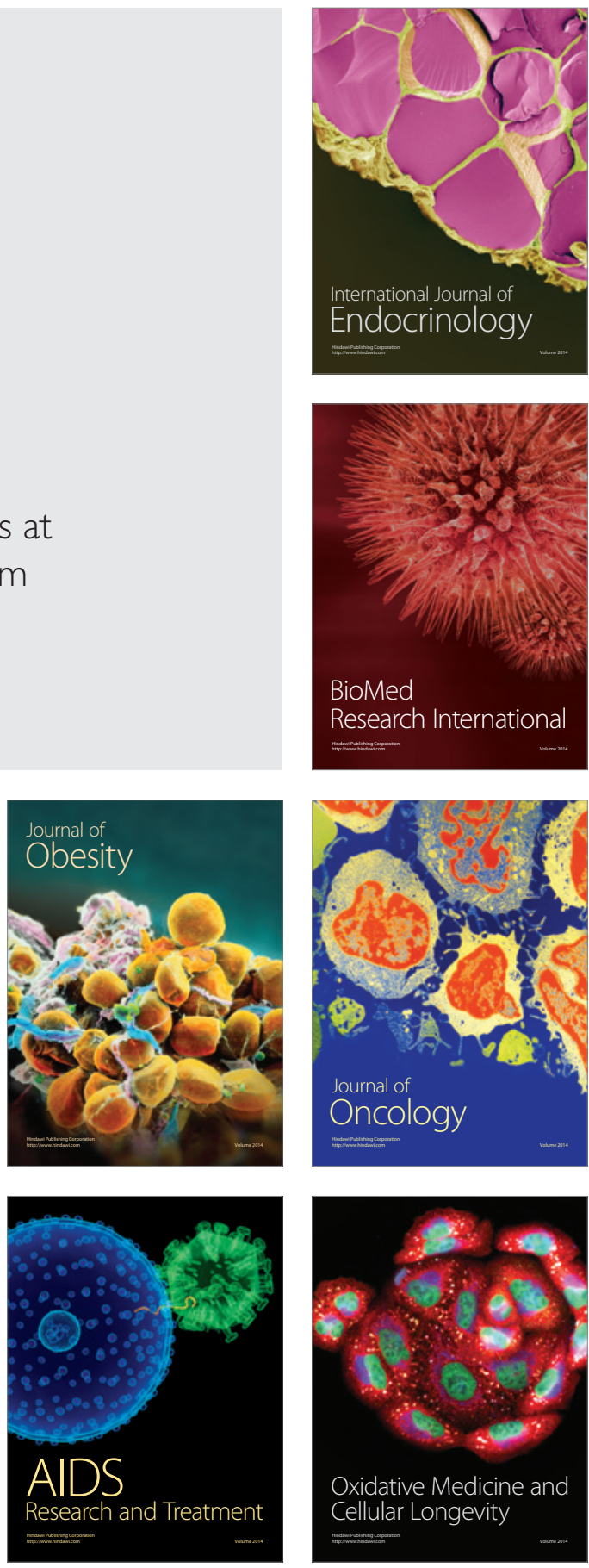